\title{
Hydrogen Sulfide Increases Nitric Oxide Production and Subsequent S-Nitrosylation in Endothelial Cells
}

\author{
Ping-Ho Chen, ${ }^{1}$ Yaw-Syan Fu, ${ }^{2}$ Yun-Ming Wang, ${ }^{3}$ Kun-Han Yang, \\ Danny Ling Wang, ${ }^{5}$ and Bin Huang ${ }^{2,6}$ \\ ${ }^{1}$ School of Dentistry, College of Dental Medicine, Kaohsiung Medical University, Kaohsiung 80708, Taiwan \\ ${ }^{2}$ Department of Biomedical Science and Environmental Biology, College of Life Science, Kaohsiung Medical University, \\ No. 100, Shihchuan 1st Road, San Ming District, Kaohsiung 80708, Taiwan \\ ${ }^{3}$ Department of Biological Science and Technology, Institute of Molecular Medicine and Bioengineering, \\ National Chiao Tung University, Hsinchu 30068, Taiwan \\ ${ }^{4}$ Institute of Biotechnology, National Cheng Kung University, Tainan 70101, Taiwan \\ ${ }^{5}$ Institute of Medical Science, College of Medicine, Tzu Chi University, Hualien County 97004, Taiwan \\ ${ }^{6}$ Department of Biological Sciences, National Sun Yat-Sen University, Kaohsiung 80424, Taiwan
}

Correspondence should be addressed to Bin Huang; huangpin2@yahoo.com.tw

Received 21 April 2014; Accepted 5 May 2014; Published 21 May 2014

Academic Editor: Li-Yeh Chuang

Copyright (C) 2014 Ping-Ho Chen et al. This is an open access article distributed under the Creative Commons Attribution License, which permits unrestricted use, distribution, and reproduction in any medium, provided the original work is properly cited.

\begin{abstract}
Hydrogen sulfide $\left(\mathrm{H}_{2} \mathrm{~S}\right)$ and nitric oxide (NO), two endogenous gaseous molecules in endothelial cells, got increased attention with respect to their protective roles in the cardiovascular system. However, the details of the signaling pathways between $\mathrm{H}_{2} \mathrm{~S}$ and NO in endothelia cells remain unclear. In this study, a treatment with NaHS profoundly increased the expression and the activity of endothelial nitric oxide synthase. Elevated gaseous NO levels were observed by a novel and specific fluorescent probe, 5-amino-2-(6hydroxy-3-oxo-3H-xanthen-9-yl)benzoic acid methyl ester (FA-OMe), and quantified by flow cytometry. Further study indicated an increase of upstream regulator for eNOS activation, AMP-activated protein kinase (AMPK), and protein kinase B (Akt). By using a biotin switch, the level of NO-mediated protein S-nitrosylation was also enhanced. However, with the addition of the NO donor, NOC-18, the expressions of cystathionine- $\gamma$-lyase, cystathionine- $\beta$-synthase, and 3 -mercaptopyruvate sulfurtransferase were not changed. The level of $\mathrm{H}_{2} \mathrm{~S}$ was also monitored by a new designed fluorescent probe, 4-nitro-7-thiocyanatobenz-2-oxa-1,3-diazole (NBD-SCN) with high specificity. Therefore, $\mathrm{NO}$ did not reciprocally increase the expression of $\mathrm{H}_{2} \mathrm{~S}$-generating enzymes and the $\mathrm{H}_{2} \mathrm{~S}$ level. The present study provides an integrated insight of cellular responses to $\mathrm{H}_{2} \mathrm{~S}$ and NO from protein expression to gaseous molecule generation, which indicates the upstream role of $\mathrm{H}_{2} \mathrm{~S}$ in modulating NO production and protein S-nitrosylation.
\end{abstract}

\section{Introduction}

Gas molecules that are produced by cells have been discussed for several decades regarding their protective role in the vascular system. Recently, the diverse physiologic actions of carbon monoxide (CO), nitric oxide (NO), and hydrogen sulfide $\left(\mathrm{H}_{2} \mathrm{~S}\right)$ and their role in preventing diseases through the mediation of gas-regulating and -sensing mechanisms have attracted a great deal of interest [1]. For example, NO plays an important role in the regulation of the cardiovascular function through a posttranslational protein Snitrosylation on the cysteine residue [2]. In our previous study, a mechanical shear flow is regarded as protective for endothelial cells (ECs), leading to a series S-nitrosylation of proteins [3]. Investigating the reported mechanisms of NO on EC protection, the NO-mediated S-nitrosylated proteins, such as F1F0-ATPase, reduced the generation of $\mathrm{Ca}^{2+}$ and ROS in mitochondria during ischemia/reperfusion injury [4]. NO was also reported to be essential in the prevention of irreversible oxidative stress and finally provided protection from several diseases including cancer, diabetes, and neuron degeneration [5-7].

The toxic effects of hydrogen sulfide $\left(\mathrm{H}_{2} \mathrm{~S}\right)$ on living organisms have been recognized for nearly 300 years. 


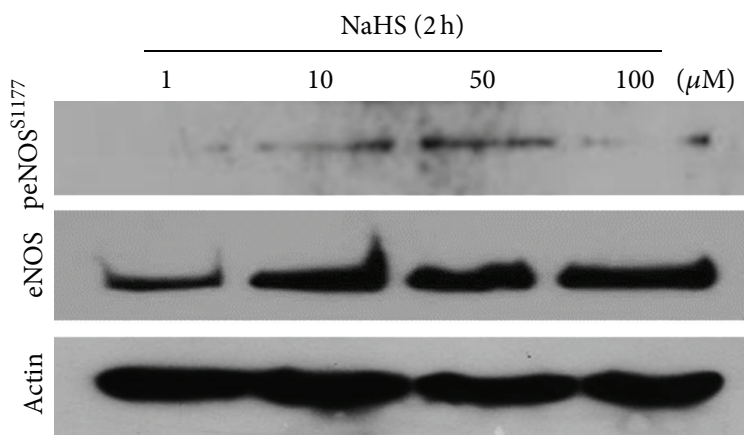

(a)

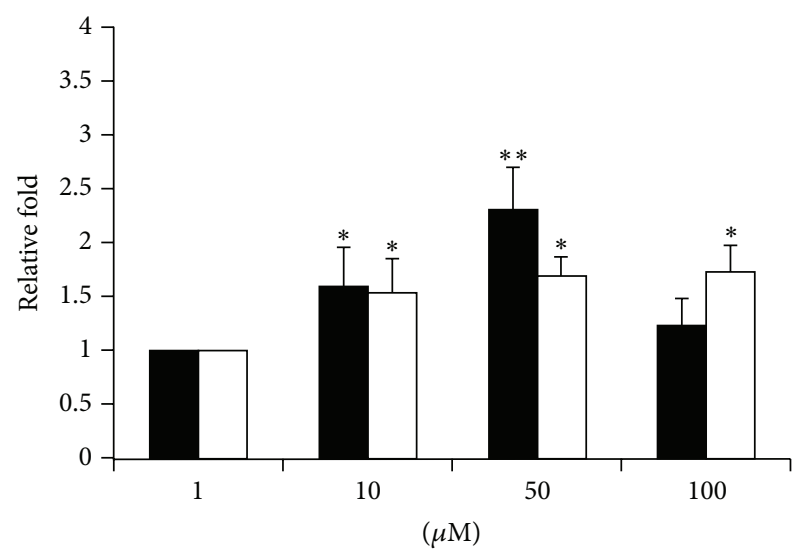

(c)

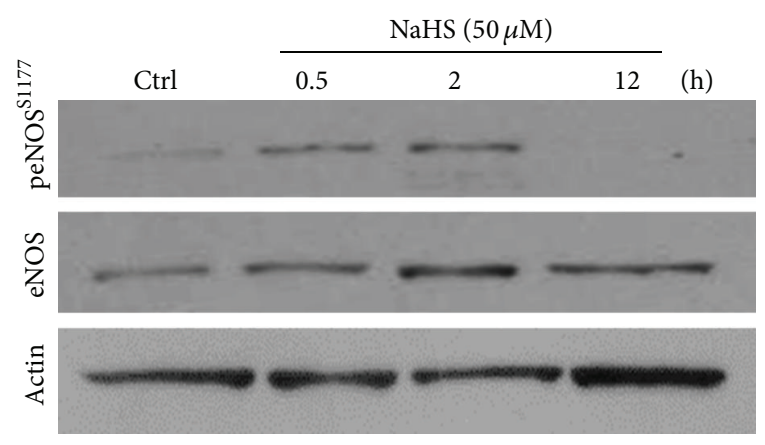

(b)

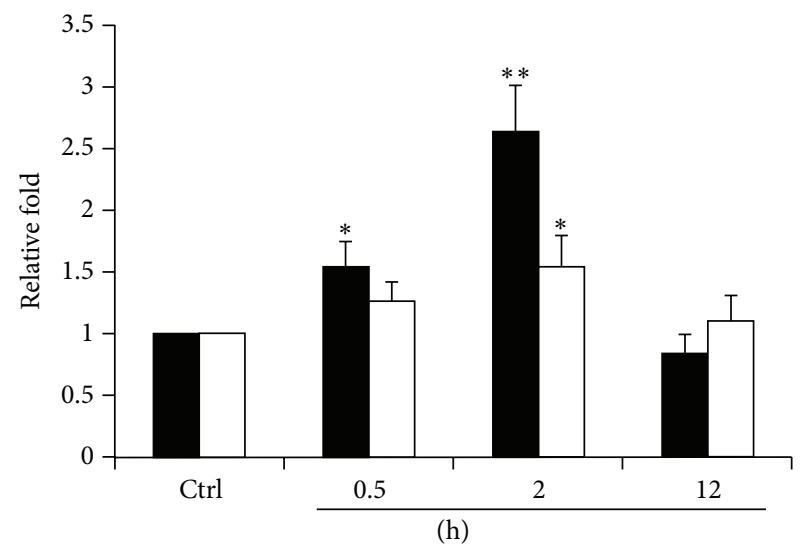

(d)

FIGURE 1: NaHS increases the expression and serine 1177 phosphorylation of eNOS. (a) ECs pretreated by diluting concentrations of NaHS $(1 \mu \mathrm{M}, 10 \mu \mathrm{M}, 50 \mu \mathrm{M}$, and $100 \mu \mathrm{M})$ for $2 \mathrm{~h}$. (b) ECs treated with NaHS $(50 \mu \mathrm{M})$ for $0.5,2$, and $12 \mathrm{~h}$. Blotted membranes were separately hybridized with eNOS and peNOSS1177 antibodies. ((c) and (d)) Relative folds of protein levels shown as means \pm S.E. compared to control. Statistical significance $\left({ }^{*} P<0.05 ;{ }^{* *} P<0.01\right)$ analyzed using Fisher's LSD.

In recent years, however, interest has been directed towards $\mathrm{H}_{2} \mathrm{~S}$ as the third gaseous mediator, which has been shown to exhibit potent vasodilatory activity both in vitro and in vivo. This is assumed to be realized by opening vascular smooth muscle $\mathrm{K}_{\mathrm{ATP}}$ channels [8]. Of the three enzymes, cystathionine- $\gamma$-lyase (CSE), cystathionine- $\beta$-synthase (CBS), and 3-mercaptopyruvate sulfurtransferase (3-MST) can utilize $\mathrm{L}$-cysteine as a substrate to produce $\mathrm{H}_{2} \mathrm{~S}$. Deficiency of $\mathrm{H}_{2} \mathrm{~S}$-producing enzymes results in some disorders such as homocystinuria, which is characterized by mental retardation, skeletal abnormalities, increased urine homocysteine, increased risks of thromboembolism, and early onset of atherosclerosis [9-11]. $\mathrm{H}_{2} \mathrm{~S}$ was also reported to protect against vascular remodeling from endothelial damage [12]. Recently, a signaling molecule for $\mathrm{H}_{2} \mathrm{~S}$ was shown to regulate vascular relaxation and angiogenesis via potassium channel S-sulfhydration [13-15].

With a similar physiological function, it is interesting to discuss the interactions between $\mathrm{H}_{2} \mathrm{~S}$ and $\mathrm{NO}$ in responding stimuli. In the reports cited above, $\mathrm{H}_{2} \mathrm{~S}$ and $\mathrm{NO}$ in synergy might regulate smooth muscle relaxation and also mitochondrial integration $[16,17] . \mathrm{H}_{2} \mathrm{~S}$ triggers late-phase preconditioning in the postischemic small intestine by an NO- and p38 MAPK-dependent pathway [18]. Despite $\mathrm{H}_{2} \mathrm{~S}$ inhibiting NO production in lipopolysaccharide-stimulated macrophages, the $\mathrm{H}_{2} \mathrm{~S}$ can also stimulate $\mathrm{NO}$ production from other cells $[19,20]$.

Because of the technical difficulty in detecting gaseous molecules, in the current study, not only monitoring the regulations of theses enzymes but also quantifying the molecules of $\mathrm{H}_{2} \mathrm{~S}$ and $\mathrm{NO}$ specifically with the new designed fluorescent probes. Therefore, we question here if $\mathrm{H}_{2} \mathrm{~S}$ has any upstream role in the regulation of endothelial NO production.

\section{Materials and Methods}

2.1. Cell Culture and Drug Treatments. The EAhy 926 cell line was kindly donated by Cora-Jean S. Edgell, University of North Carolina, Chapel Hill. EAhy 926 cells were cultured in DMEM supplemented with fetal bovine serum (FBS, 10\%), streptomycin $(100 \mu \mathrm{g} / \mathrm{mL})$, and penicillin $(100 \mathrm{U} / \mathrm{mL})$. ECs were replaced by the same medium containing $2 \%$ FBS and incubated overnight prior to the experimental $\mathrm{NaHS}$ and NOC-18 treatments.

2.2. Cell Lysis and Protein Extraction. ECs were washed with cord buffer after treatment $[\mathrm{NaCl}(0.14 \mathrm{M}), \mathrm{KCl}(4 \mathrm{mM})$, 

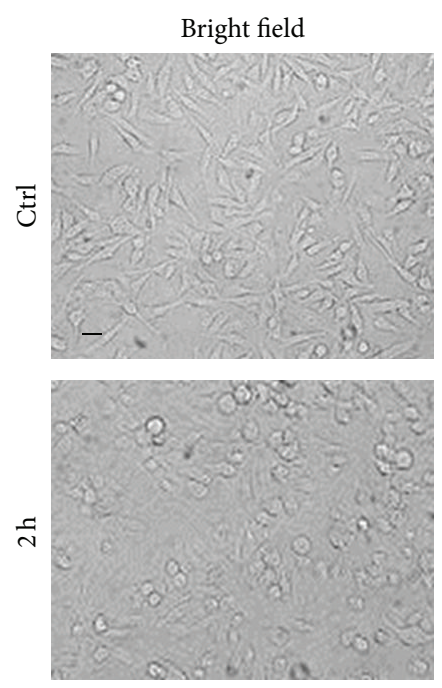

(a)
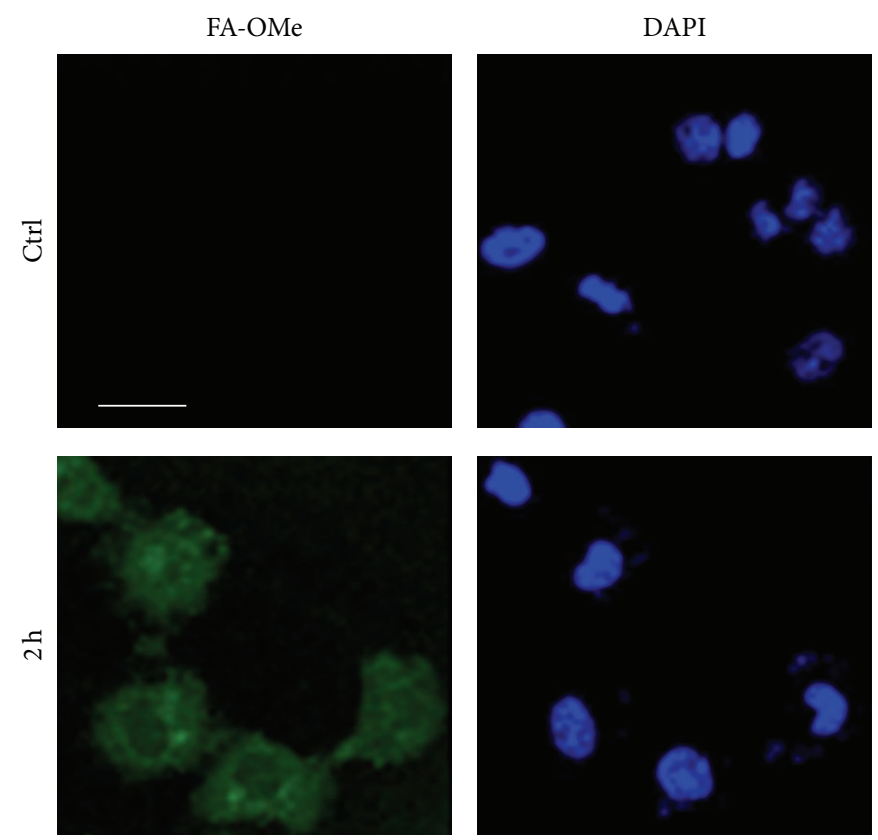

(c)
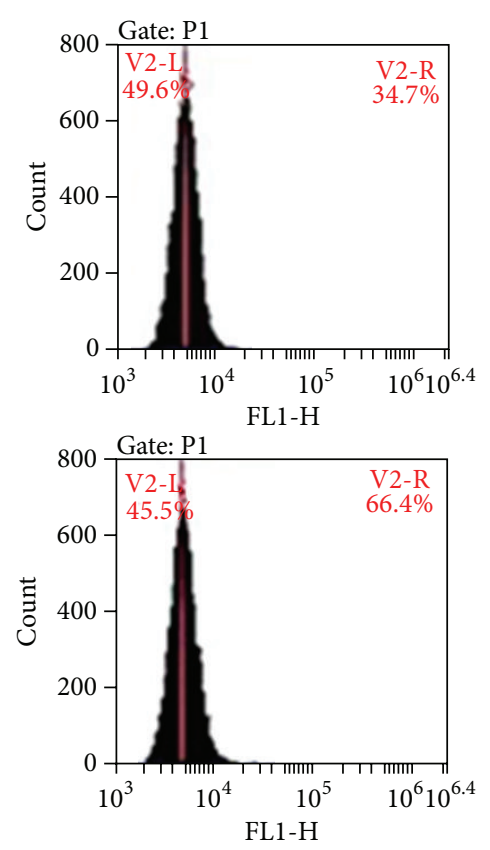

(b)
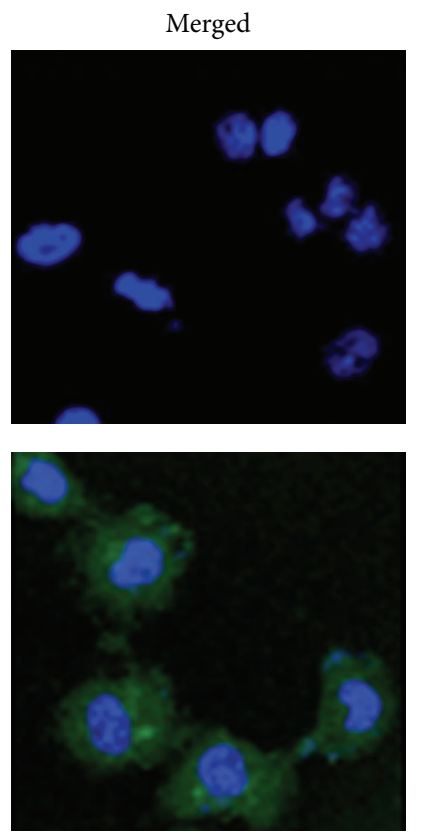

Figure 2: Elevated NO levels monitored by specific fluorescent probes. (a) ECs treated with NaHS (50 $\mu \mathrm{M}$ ) for $2 \mathrm{~h}$ stained by FA-OMe and observed by fluorescent microscopy. (b) FA-OMe signals calculated by flow cytometry. (c) FA-OMe signals observed by confocal microscopy. $\operatorname{Bar}=20 \mu \mathrm{m}$.

glucose (11 mM), and HEPES (10 mM, pH 7.4)] and then lysed with $100 \mu \mathrm{L}$ of lysis buffer [HEPES (250 mM, pH 7.7), EDTA $(1 \mathrm{mM})$, neocuproine $(0.1 \mathrm{mM})$, and CHAPS $(0.4 \%$, $\mathrm{w} / \mathrm{v})]$. After centrifugation, protein supernatant was collected and protein concentrations were determined with BCA assay reagent (Thermo Fisher Scientific Inc., Rockford, IL, USA).
2.3. Western Blot Analysis. Forty micrograms of cell lysates with various treatments were mixed with an equal volume of sample buffer [Tris- $\mathrm{HCl}$ (62.5 mM, pH 6.8), SDS (3\%, w/v), 2 -mercaptoethanol $(5 \%, \mathrm{v} / \mathrm{v})$, and glycerol $(10 \%, \mathrm{v} / \mathrm{v})]$ and then separated by SDS-PAGE. The gel was transferred to PVDF membranes (Millipore, MA, USA) and immunoblotted with antibodies: eNOS (1:3000; Cell Signaling Tech., MA, 


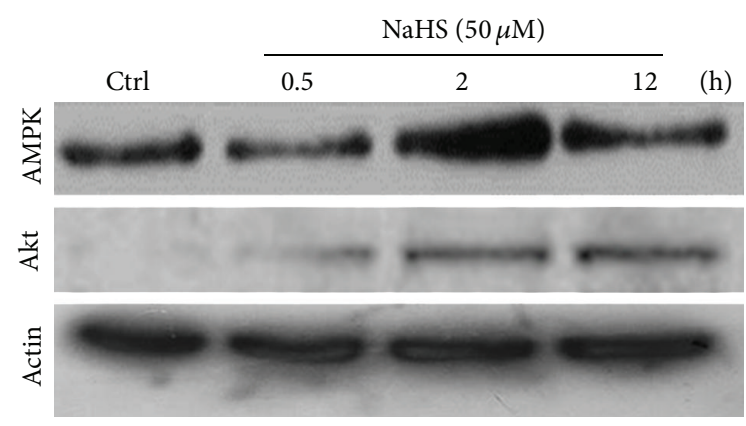

(a)

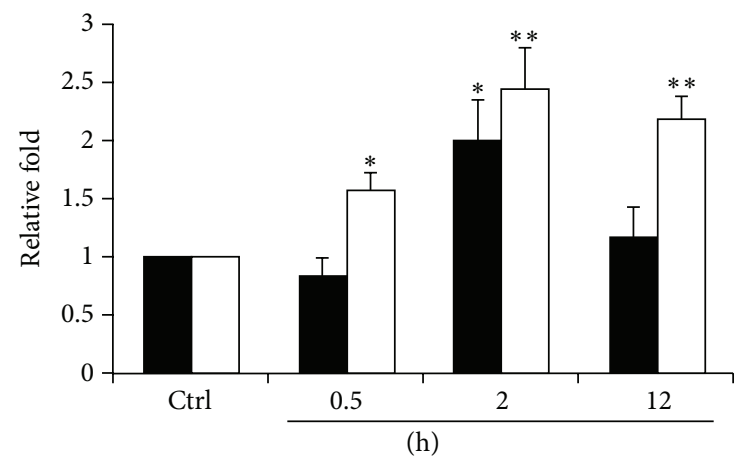

AMPK

$\square$ Akt

(b)

FIGURE 3: The expression levels of AMPK and Akt in the presence of NaHS. (a) ECs treated with NaHS $(50 \mu \mathrm{M})$ for $0.5,2$, and $12 \mathrm{~h}$. The blotted membranes hybridized with AMPK antibody. (b) Relative folds of protein levels shown as means \pm S.E. compared to control. Statistical significance $\left({ }^{*} P<0.05 ;{ }^{* *} P<0.01\right)$ analyzed using Fisher's LSD.

USA), peNOS ${ }^{S 1177}$ (1:2000; Cell Signaling Tech.), AMPK (1:3000; Cell Signaling Tech.), Akt (1:2000; Cell Signaling Tech.), cystathionine- $\gamma$-lyase (CSE, 1:1000; Abnova, Taipei, Taiwan), cystathionine- $\beta$-synthase (CBS, 1:1000; Abnova), and 3-mercaptopyruvate sulfurtransferase (3-MST, 1:1000; Abcam, Cambridge, UK). The membranes were visualized with the SuperSignal West Femto reagent (Thermo Fisher Scientific, IL, USA) on X-ray films. The images from Xray films were scanned using a digital scanner (Microtek International Inc.) and the density was calculated by the Progenesis Samespots v2.0 software (NonLinear Dynamics, Newcastle, UK).

2.4. Application of Fluorescent Probes and Imaging Conditions. For NO detection, 5-amino-2-(6-hydroxy-3-oxo$3 \mathrm{H}$-xanthen-9-yl)benzoic acid methyl ester (FA-OMe) was designed [21]. ECs with NaHS treatment were coincubated with $10 \mu \mathrm{M}$ of FA-OMe for $4 \mathrm{~h}$ prior to imaging. The ECs were washed three times with PBS buffer and then bathed in $2 \mathrm{~mL}$ of PBS. The images were obtained by the fluorescence microscope ( $\lambda$ ex $460 \mathrm{~nm}, \lambda$ em $524 \mathrm{~nm}$; Axiovert
$40 \mathrm{CFL}$, Zeiss). As for 4-nitro-7-thiocyanatobenz-2-oxa-1,3diazole (NBD-SCN) that was used for detecting $\mathrm{H}_{2} \mathrm{~S}$, the cells were incubated with $5 \mu \mathrm{M}$ NBD-SCN for $30 \mathrm{~min}$ and then subjected to fluorescence microscope ( $\lambda$ ex $460 \mathrm{~nm}, \lambda \mathrm{em}$ $550 \mathrm{~nm}$ ) [22]. For confocal fluorescence images study, ECs were seeded at a density of $2 \times 10^{5}$ cells/well on cover glasses $\left(24 \times 24 \mathrm{~mm}^{2}\right)$ and grown for $24 \mathrm{~h}$. The cells with $10 \mu \mathrm{M}$ of FAOMe incubation were fixed with $4 \%$ formaldehyde solution for $20 \mathrm{~min}$ at room temperature. Cell nuclei were stained with 40,6-diamidino-2-phenylindole (DAPI). Cover glasses containing fixed ECs were mounted in a mixture of PBS and glycerol $(1: 1)$ on a microscopic slide. The cells were observed using a laser scanning confocal imaging system (Olympus FluoView 300) consisting of Olympus BX51 microscope and a $20 \mathrm{~mW}$ output argon ion laser.

2.5. Flow Cytometry Assay. After fluorescence microscope observation, the ECs were washed twice with PBS and detached by tryptic reaction. ECs were collected by centrifugation and then resuspended in PBS. The fluorescence was immediately measured by the Accuri C6 flow cytometer (BD, NJ, USA) with excitation and emission settings of 488 and $530 \mathrm{~nm}$, respectively. The fluorescence strength was obtained from $1 \times 10^{4}$ cells and statistically calculated from three repeats.

2.6. Evaluation of Protein S-Nitrosylation. The cell lysates $(200 \mu \mathrm{g})$ after NaHS treatment were blocked by methyl methanethiosulfonate (MMTS), reduced by ascorbate, and labelled by biotin according to reported guideline [23]. The biotinylated lysates were then subjected to a reductantfree SDS-PAGE and western blotted with streptavidin-HRP $(1: 3000)$ following a previous study [24].

\section{Results and Discussion}

3.1. NaHS Increased the Protein Level of eNOS and the Phosphorylation on Serine 1177 Residue. Endothelial nitric oxide synthase (eNOS) is responsible for endothelial nitric oxide (NO) production and the enzyme activity is reported to be highly affected by posttranslational phosphorylation on serine 1177 residue (S1177) [25]. In this study, with the treatment of different concentrations of NaHS $(1 \sim 100 \mu \mathrm{M})$, we found that $50 \mu \mathrm{M}$ of NaHS can significantly enhance both the eNOS expression and the phosphorylation of the serine 1177 residue (peNOS ${ }^{S 1177}$ ) (Figures 1(a) and 1(c)). This concentration conforms well with several vascular research articles [26]. At this concentration, the highest expression level of eNOS and peNOS ${ }^{S 1177}$ was observed at 2 hours (Figures 1(b) and 1(d)).

3.2. Cellular NO Was Precisely Determined by Specific Fluorescent Probes. In addition to the expression of eNOS, the levels of NO molecules were further measured by the specific fluorescent probe FA-OMe. This can distinguish NO and other reactive oxygen species (ROS) from reactive nitrogen species (RNS) [21]. After NaHS treatment, the NO level was increased from $34.7 \pm 2.9 \%$ to $66.4 \pm 3.8 \%$ at 2 hours 


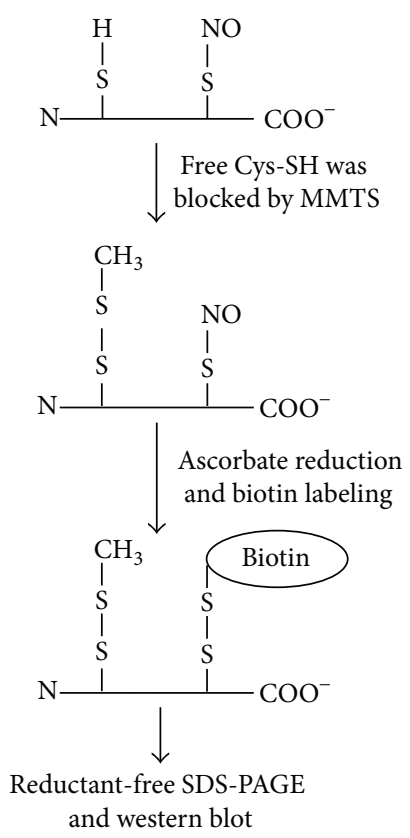

(a)

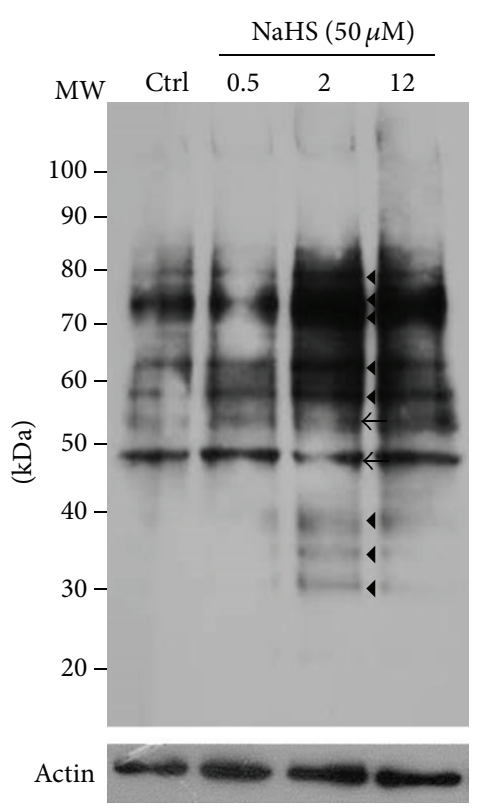

(b)

FIGURE 4: Detection of protein S-nitrosylation. (a) Scheme representing the procedures of modified biotin switch. Biotin-labeled lysates were subjected to SDS-PAGE without any reducing agents in the buffers. (b) ECs lysate $(100 \mu \mathrm{g})$ treated with NaHS (50 $\mu \mathrm{M})$ for 0.5 , 2, and $12 \mathrm{~h}$ separated by SDS-PAGE and the blotted membranes were hybridized with streptavidin-HRP. Triangle indicates proteins with increased S-nitrosylation. Arrow head indicates proteins with decreased S-nitrosylation.

(Figures 2(a) and 2(b)). By using confocal microscopy, despite the fact that the basal fluorescence in the control treatment was difficult to see, the broadly distributed NO was observed in the cytosol and also in the nuclei (Figure 2(c)).

\subsection{The Expression Profiles of AMPK and Akt in the Presence of} $\mathrm{H}_{2} \mathrm{~S}$. $5^{\prime}$ AMP-activated protein kinase (AMPK) is an enzyme that plays a role in cellular energy homeostasis. Besides protein kinase B (Akt), AMPK is also reported to activate eNOS by phosphorylating Ser1177 in response to various stimuli [27]. In the current study, $\mathrm{H}_{2} \mathrm{~S}$ increased the protein level of AMPK at $2 \mathrm{~h}$ and returned to a basal level at $12 \mathrm{~h}$. However, sustainable expressions of Akt were observed from 0.5 to $12 \mathrm{~h}$ (Figures 3(a) and 3(b)). This indicated that $\mathrm{H}_{2} \mathrm{~S}$ can stimulate eNOS activity through AMPK and Akt pathways. Similar findings were also reported recently [28, 29].

\section{4. $\mathrm{H}_{2} \mathrm{~S}$-Increased Bioavailability of NO That Can Enhance} Protein S-Nitrosylation. According to previous data, we confirmed that $\mathrm{NO}$ level got elevated by $\mathrm{H}_{2} \mathrm{~S}$. Since protein $\mathrm{S}$-nitrosylation/denitrosylation is regarded as important in cardioprotection, its investigation of protein S-nitrosylation is, hence, important for applied medical purposes $[2,3,30]$. By using a modified biotin switch, we could identify at least 8 groups of increased S-nitrosoproteins and 2 groups of decreased S-nitrosoproteins (Figure 4). With the excellent performance in analyzing S-nitrosoproteins, mass spectrometry will be introduced in further identification of these proteins [24].
3.5. NO Did Not Reciprocally Increase the Expression of $\mathrm{H}_{2} \mathrm{~S}$ Generating Enzymes and the $\mathrm{H}_{2} \mathrm{~S}$ Level. After confirming that $\mathrm{H}_{2} \mathrm{~S}$ can increase $\mathrm{NO}$ at the cellular level, we also examined whether $\mathrm{NO}$ can be synchronized at elevated $\mathrm{H}_{2} \mathrm{~S}$ levels. As shown in Figure 5, three key enzymes are involved in the cellular $\mathrm{H}_{2} \mathrm{~S}$ synthesis: CSE, CBS, and 3-MST. These were not changed by NOC-18 treatment (Figures 5(a) and 5(b)). Although several studies indicated that $\mathrm{H}_{2} \mathrm{~S}$-generating enzymes can also be exerted by NO [31], we could not find differences in our microscopic and flow cytometric analysis $(46.0 \pm 3.1 \%$ and $43.3 \pm 4.8 \%$ separately) using NBD-SCN fluorescence probe (Figures 5(c) and 5(d)). The reported study demonstrated that $\mathrm{H}_{2} \mathrm{~S}$ promotes $\mathrm{NO}$ production in ECs via the activation of a cascade of phosphorylation events, starting from p38 MAPK and Akt to eNOS, and this can be through NO-dependent or NO-independent mechanisms cascade. Thus, $\mathrm{H}_{2} \mathrm{~S}$ may be a key regulator for angiogenic signalling pathways, whether they required NO or not [32]. This might indicate that NO works as a downstream gaseous transmitter in the endothelium.

\section{Conclusion}

In the present study, hydrogen sulfide increased nitric oxide production. This was not only concluded by studying related enzymes, but also confirmed directly by detecting the final products where NO levels were observed by a novel and specific fluorescent probe, FA-OMe, and quantified by flow cytometry. The level of $\mathrm{H}_{2} \mathrm{~S}$ was also monitored by a new 


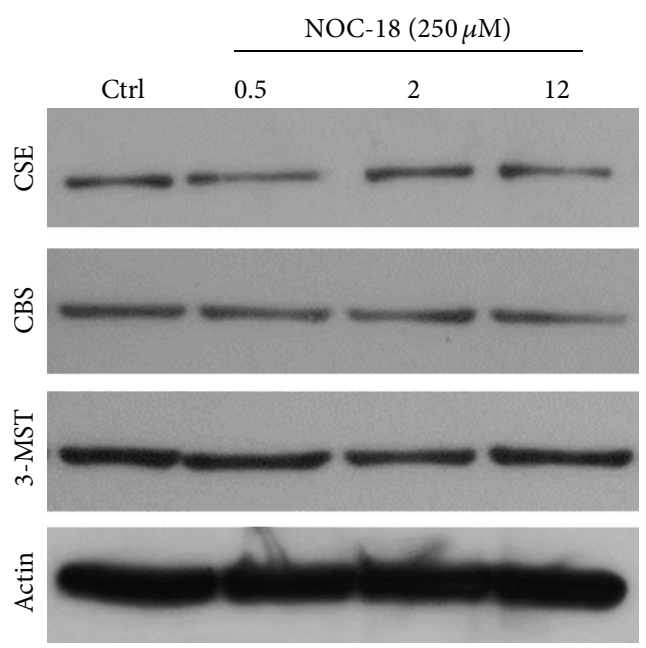

(a)

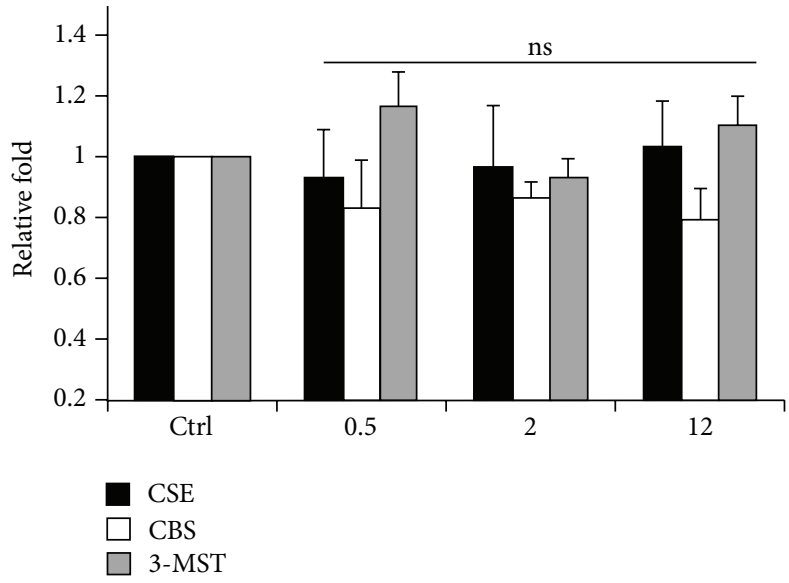

(b)

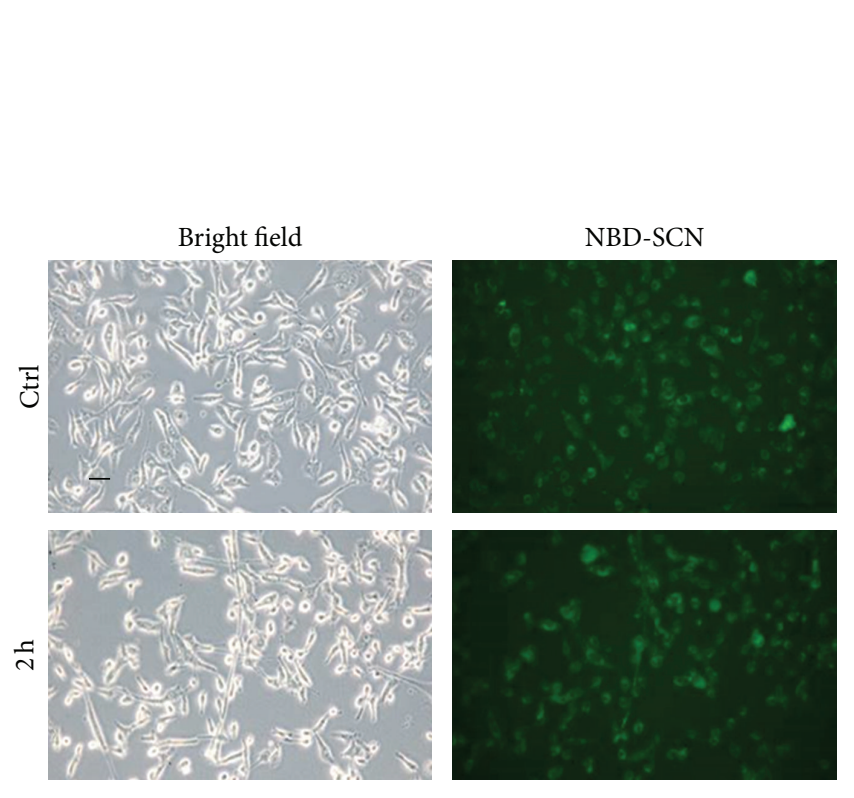

(c)
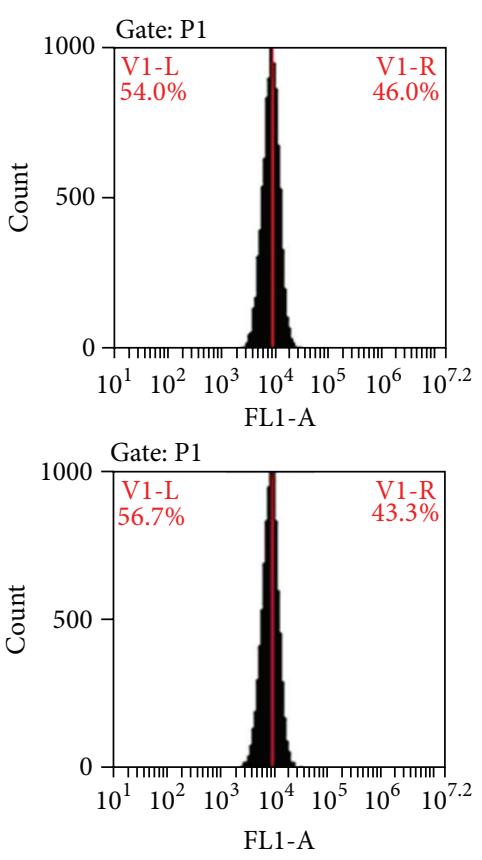

(d)

FIGURE 5: Investigation of $\mathrm{H}_{2} \mathrm{~S}$ biosynthesis under the treatment of NO. (a) ECs which treated NO donor, NOC-18 (250 $\left.\mu \mathrm{M}\right)$, for 0.5 , 2, and $12 \mathrm{~h}$ were subjected to western blot analysis with CSE, CBS, and 3-MST antibodies. (b) The statistic data showed that no significance $(P=\mathrm{ns})$ was observed between treatments. (c) NBD-SCN was applied to detect cellular $\mathrm{H}_{2} \mathrm{~S}$ level specifically. (d) Fluorescent signals were calculated by flow cytometry.

designed fluorescent probe, NBD-SCN, with high specificity. The present study provides an integrated insight of cellular responses to two gaseous molecules from protein expression to gaseous molecule generation, which indicates the upstream role of $\mathrm{H}_{2} \mathrm{~S}$ in modulating $\mathrm{NO}$ production and protein S-nitrosylation.

\section{Conflict of Interests}

The authors declare no conflict of interests.

\section{Authors' Contribution}

Ping-Ho Chen and Yaw-Syan Fu contributed equally to this paper.

\section{Acknowledgments}

The authors thank Dr. Hans-Uwe Dahms for critical reading of the paper. This study was supported by a Grant from the National Science Council (NSC 101-2320-B-037-041). 
They are grateful to the Center for Resources, Research \& Development of Kaohsiung Medical School for the support of fluorescent imaging.

\section{References}

[1] M. Kajimura, R. Fukuda, R. M. Bateman, T. Yamamoto, and M. Suematsu, "Interactions of multiple gas-transducing systems: hallmarks and uncertainties of $\mathrm{CO}, \mathrm{NO}$, and $\mathrm{H}_{2} \mathrm{~S}$ Gas Biology," Antioxidants \& Redox Signaling, vol. 13, no. 2, pp. 157-192, 2010.

[2] J. Sun and E. Murphy, "Protein S-nitrosylation and cardioprotection," Circulation Research, vol. 106, no. 2, pp. 285-296, 2010.

[3] B. Huang, S. C. Chen, and D. L. Wang, "Shear flow increases S-nitrosylation of proteins in endothelial cells," Cardiovascular Research, vol. 83, no. 3, pp. 536-546, 2009.

[4] S. Shiva, M. N. Sack, J. J. Greer et al., "Nitrite augments tolerance to ischemia/reperfusion injury via the modulation of mitochondrial electron transfer," The Journal of Experimental Medicine, vol. 204, no. 9, pp. 2089-2102, 2007.

[5] Y.-Y. Chen, H.-M. Chu, K.-T. Pan et al., "Cysteine Snitrosylation protects protein-tyrosine phosphatase $1 \mathrm{~B}$ against oxidation-induced permanent inactivation," The Journal of Biological Chemistry, vol. 283, no. 50, pp. 35265-35272, 2008.

[6] T. Nakamura and S. A. Lipton, "Emerging roles of Snitrosylation in protein misfolding and neurodegenerative diseases," Antioxidants \& Redox Signaling, vol. 10, no. 1, pp. 87-101, 2008.

[7] B. Lima, M. T. Forrester, D. T. Hess, and J. S. Stamler, "Snitrosylation in cardiovascular signaling," Circulation Research, vol. 106, no. 4, pp. 633-646, 2010.

[8] S. Mani, A. Untereiner, L. Wu, and R. Wang, "Hydrogen sulfide and the pathogenesis of atherosclerosis," Antioxidants \& Redox Signaling, vol. 20, no. 5, pp. 805-817, 2014.

[9] C. A. Wagner, "Hydrogen sulfide: a new gaseous signal molecule and blood pressure regulator," Journal of Nephrology, vol. 22, no. 2, pp. 173-176, 2009.

[10] G. Yang, L. Wu, B. Jiang et al., " $\mathrm{H}_{2} \mathrm{~S}$ as a physiologic vasorelaxant: hypertension in mice with deletion of cystathionine $\gamma$ lyase," Science, vol. 322, no. 5901, pp. 587-590, 2008.

[11] Y. Wang, X. Zhao, H. Jin et al., "Role of hydrogen sulfide in the development of atherosclerotic lesions in apolipoprotein e knockout mice," Arteriosclerosis, Thrombosis, and Vascular Biology, vol. 29, no. 2, pp. 173-179, 2009.

[12] T. P. Vacek, W. Gillespie, N. Tyagi, J. C. Vacek, and S. C. Tyagi, "Hydrogen sulfide protects against vascular remodeling from endothelial damage," Amino Acids, vol. 39, no. 5, pp. 1161-1169, 2010.

[13] A. Papapetropoulos, A. Pyriochou, Z. Altaany et al., "Hydrogen sulfide is an endogenous stimulator of angiogenesis," Proceedings of the National Academy of Sciences of the United States of America, vol. 106, no. 51, pp. 21972-21977, 2009.

[14] A. K. Mustafa, M. M. Gadalla, N. Sen et al., " $\mathrm{H}_{2} \mathrm{~S}$ signals through protein S-Sulfhydration," Science Signaling, vol. 2, no. 96, Article ID ra72, 2009.

[15] A. K. Mustafa, G. Sikka, S. K. Gazi et al., "Hydrogen sulfide as endothelium-derived hyperpolarizing factor sulfhydrates potassium channels," Circulation Research, vol. 109, no. 11, pp. 1259-1268, 2011.

[16] R. Hosoki, N. Matsuki, and H. Kimura, "The possible role of hydrogen sulfide as an endogenous smooth muscle relaxant in synergy with nitric oxide," Biochemical and Biophysical Research Communications, vol. 237, no. 3, pp. 527-531, 1997.

[17] F. Bouillaud and F. Blachier, "Mitochondria and sulfide: a very old story of poisoning, feeding, and signaling?" Antioxidants \& Redox Signaling, vol. 15, no. 2, pp. 379-391, 2011.

[18] M. Yusof, K. Kamada, T. Kalogeris, F. Spencer Gaskin, and R. J. Korthuis, "Hydrogen sulfide triggers late-phase preconditioning in postischemic small intestine by an NO- and p38 MAPKdependent mechanism," American Journal of Physiology - Heart and Circulatory Physiology, vol. 296, no. 3, pp. H868-H876, 2009.

[19] G.-S. Oh, H.-O. Pae, B.-S. Lee et al., "Hydrogen sulfide inhibits nitric oxide production and nuclear factor- $\kappa \mathrm{B}$ via heme oxygenase-1 expression in RAW264.7 macrophages stimulated with lipopolysaccharide," Free Radical Biology \& Medicine, vol. 41, no. 1, pp. 106-119, 2006.

[20] L. Grossi, "Hydrogen sulfide induces nitric oxide release from nitrite," Bioorganic and Medicinal Chemistry Letters, vol. 19, no. 21, pp. 6092-6094, 2009.

[21] T.-W. Shiue, Y.-H. Chen, C.-M. Wu et al., "Nitric oxide turn-on fluorescent probe based on deamination of aromatic primary monoamines," Inorganic Chemistry, vol. 51, no. 9, pp. 54005408, 2012.

[22] Y.-H. Chen, J.-C. Tsai, T.-H. Cheng, S.-S. Yuan, and Y.M. Wang, "Sensitivity evaluation of NBD-SCN towards cysteine/homocysteine and its bioimaging applications," Biosensors \& Bioelectronics, vol. 56, pp. 117-123, 2014.

[23] S. R. Jaffrey and S. H. Snyder, "The biotin switch method for the detection of S-nitrosylated proteins," Science's STKE: Signal Transduction Knowledge Environment, vol. 2001, no. 86, article Pl1, 2001.

[24] B. Huang, C. L. Liao, Y. P. Lin, S. C. Chen, and D. L. Wang, "S-nitrosoproteome in endothelial cells revealed by a modified biotin switch approach coupled with western blot-based twodimensional gel electrophoresis," Journal of Proteome Research, vol. 8, no. 10, pp. 4835-4843, 2009.

[25] P. M. Bauer, D. Fulton, Y. C. Boo et al., "Compensatory phosphorylation and protein-protein interactions revealed by loss of function and gain of function mutants of multiple serine phosphorylation sites in endothelial nitric-oxide synthase," The Journal of Biological Chemistry, vol. 278, no. 17, pp. 14841-14849, 2003.

[26] C. Szabó and A. Papapetropoulos, "Hydrogen sulphide and angiogenesis: mechanisms and applications," British Journal of Pharmacology, vol. 164, no. 3, pp. 853-865, 2011.

[27] S. Dimmeler, I. Fleming, B. Fisslthaler, C. Hermann, R. Busse, and A. M. Zeiher, "Activation of nitric oxide synthase in endothelial cells by Akt-dependent phosphorylation," Nature, vol. 399, no. 6736, pp. 601-605, 1999.

[28] B. L. Predmore, D. Julian, and A. J. Cardounel, "Hydrogen sulfide increases nitric oxide production from endothelial cells by an Akt-dependent mechanism," Frontiers in Physiology, vol. 2, article 104, 2011.

[29] P. Manna and S. K. Jain, "L-cysteine and hydrogen sulfide increase PIP3 and AMPK/PPAR $\gamma$ expression and decrease ROS and vascular inflammation markers in high glucose treated human U937 monocytes," Journal of Cellular Biochemistry, vol. 114, no. 10, pp. 2334-2345, 2013.

[30] B. Huang, F. A. Li, C. H. Wu, and D. L. Wang, "The role of nitric oxide on rosuvastatin-mediated S-nitrosylation and translational proteomes in human umbilical vein endothelial cells," Proteome Science, vol. 10, no. 1, article 43, 2012. 
[31] C. Coletta, A. Papapetropoulos, K. Erdelyi et al., "Hydrogen sulfide and nitric oxide are mutually dependent in the regulation of angiogenesis and endothelium-dependent vasorelaxation," Proceedings of the National Academy of Sciences of the United States of America, vol. 109, no. 23, pp. 9161-9166, 2012.

[32] Z. Altaany, G. Yang, and R. Wang, "Crosstalk between hydrogen sulfide and nitric oxide in endothelial cells," Journal of Cellular and Molecular Medicine, vol. 17, no. 7, pp. 879-888, 2013. 

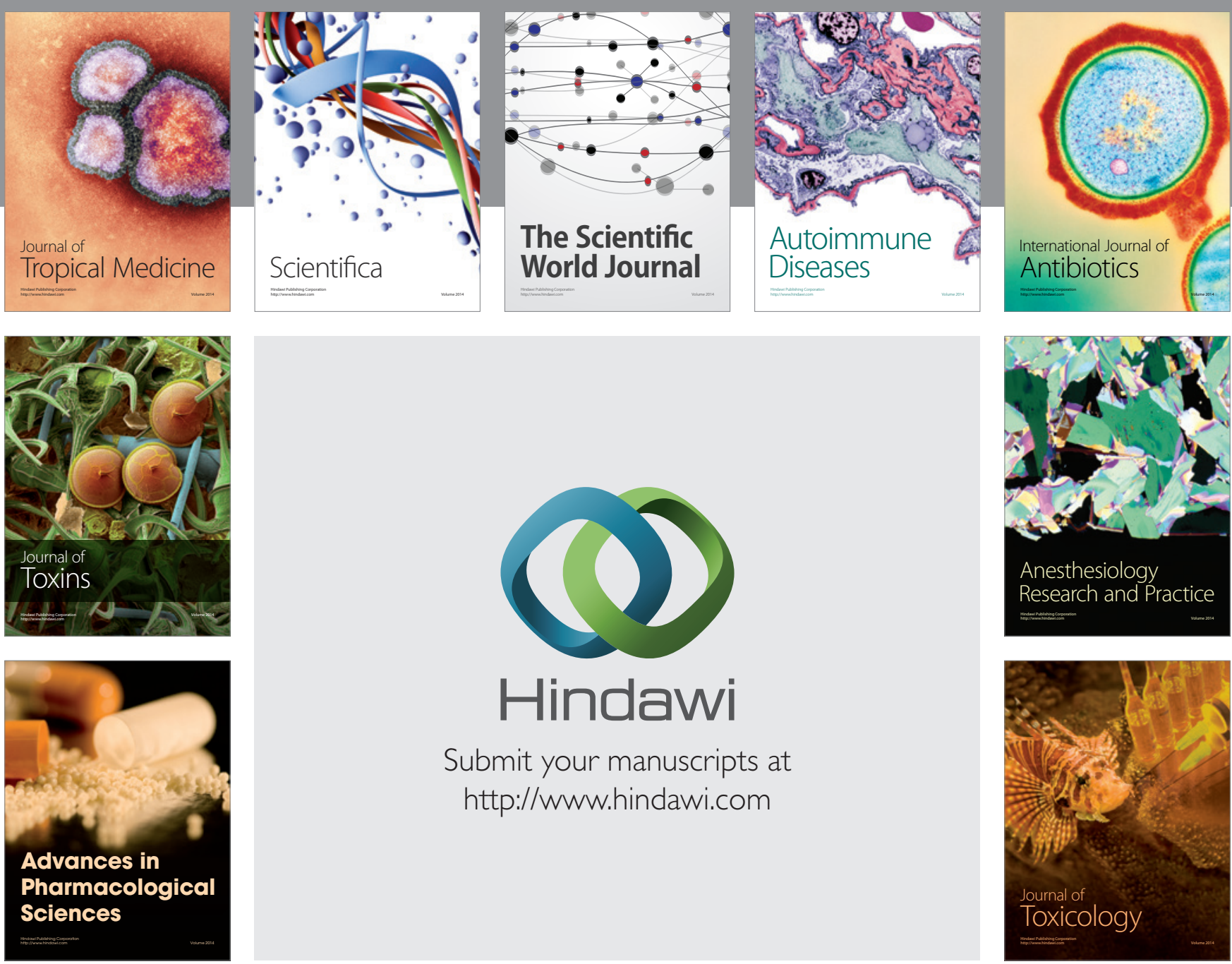

\section{Hindawi}

Submit your manuscripts at

http://www.hindawi.com
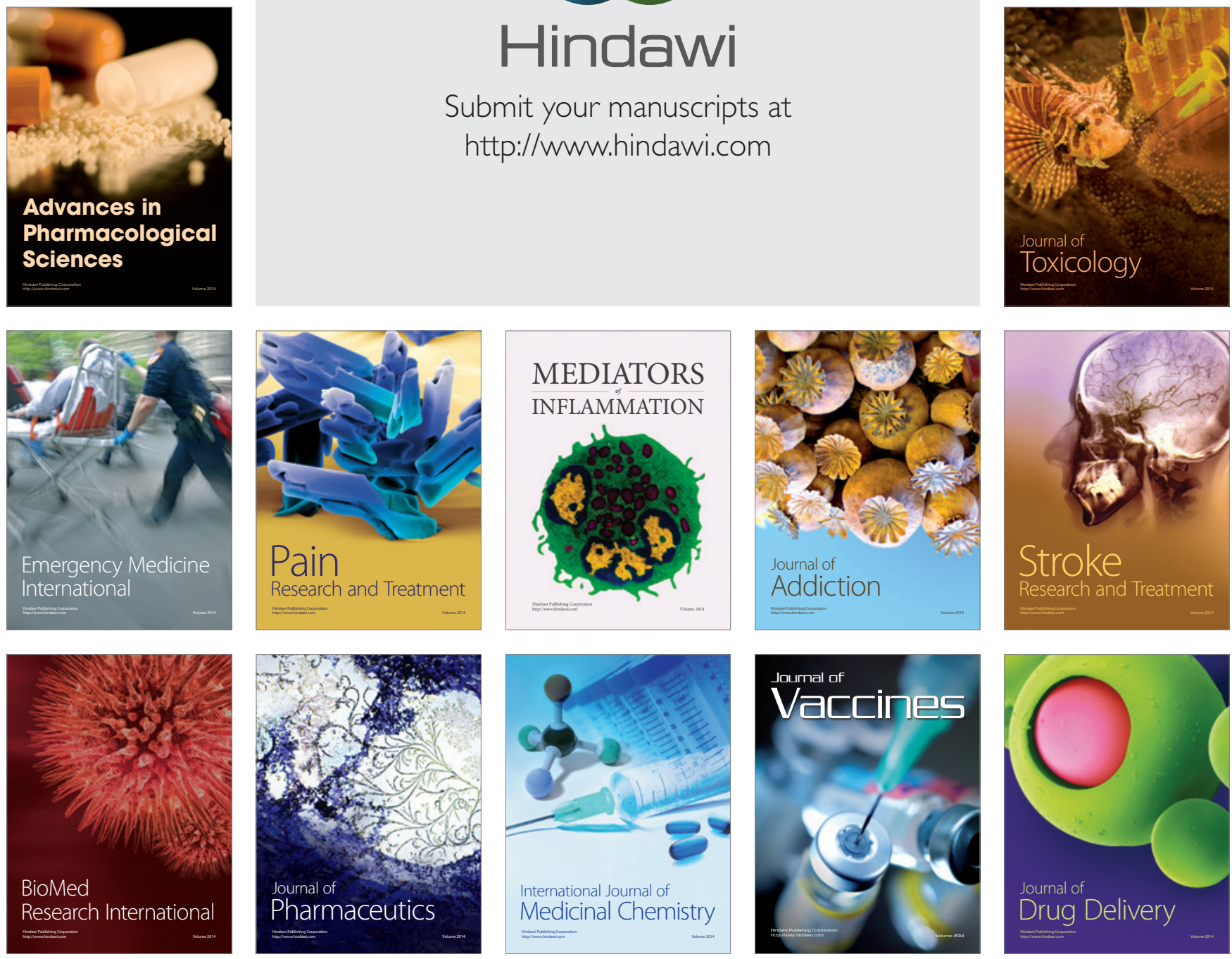